\title{
Microcontroller Controlled Fruit Drying System Using Alternative Energy Sources
}

\author{
Emine Canan Gunay Demirel \\ Canakkale Vocational School of Technical Sciences, Canakkale Onsekiz Mart University \\ PO box 17100, Canakkale, Turkey \\ E-mail: ecanan1977@gmail.com \\ Kamil Akgun \\ Canakkale Vocational School of Technical Sciences, Canakkale Onsekiz Mart University \\ PO box 17100, Canakkale, Turkey \\ E-mail: akgun@comu.edu.tr
}

This work was supported by Canakkale Onsekiz Mart University the Scientific Research Coordination Unit. Project Code: FHD-2019-2881

\begin{abstract}
In this study, solar, one of the renewable energy sources, was used to obtain electricity and heat energy. In the system we created, using the heat insulated material, solar beam collecting cage (GITK) and drying oven were made with air inlet-outlet. These were then properly combined and feet added. Two fans were placed at the GITK air inlet end and forced air flow was provided when necessary. This process is done with microcontroller controlled circuit (MKD) which we designed to stop and stop the fans. Respectively; one temperature and humidity sensor was placed in the GITK entrance, in the middle of the GITK and drying oven, and its connection to MKD was made. With the control software, the temperature and humidity values of all three sensors are compared and the fans are checked to see if they are working. Thus, the heated air inside the GITK passes to the drying section and dehumidifies the products and exits from the above chimney. The electrical energy required for the operation of fans and MKD is provided from a $10 \mathrm{~W}$ solar panel. The microcontroller records the temperature and humidity values in text format at two hour intervals. The system can be monitored and controlled through the web page with wificonnected communication devices. Plum and pear drying attempts were made to test the system's operability.
\end{abstract}

Keywords: Solar Energy, Fruit Drying, Nodemcu, ESP8266

DOI: $10.7176 /$ JSTR/6-07-11

\section{Introduction}

One of the methods of preserving food for a long time is drying (Gülçimen F., Durmuş A., Durmuş A. 2010). In this method, most of the sun is used. However, since uncontrolled drying in open environment can result in large losses in the quality of the product, a closed and controlled environment is required to obtain a quality product. Drying time can vary depending on the initial moisture content and final moisture content. This period occurs according to the weight values at the first humidity and the weight values at the last humidity (Ertekin, C., Yald1z, O. 1998). Although fruit and vegetable drying systems have different applications, they basically work as follows. The product is made ready for drying and placed on the grates. The heat in the drying section is raised to the appropriate temperature for the product. By creating an air flow inside, it is ensured that hot, dry air is passed over the products and dehumidified and the moist air is removed from the environment. There are many studies using solar energy and, accordingly, air solar collectors to reduce energy costs in drying (Ceylan, İ., Aktaş, M., Doğan, H. 2006. Hürdoğan E., et al. 2013). Although most of them have the same logic of operation, it has set an example for our study in terms of usability especially in rural areas considering the size and cost of our country (Özbalta N., et al. 2003). In order for the drying process to be faster, the air must be forced to move in the system. This can be done by using electrically powered fans (Apaydın, N. 2007. Tosun, N., Bayındır, H., Aydın, H. 2009). In order to make the system more efficient, due to its thermal insulation and easy workability, wood materials etc. available. In addition, reflectors can be added to intensify sunlight on the solar collector panel. The fresh air entering inside is heated; After the products 
are passed over and dehumidified, collapsible lids and chimney system can be made for the removal of moist air (Mutlu, A., Ergüneş, G. 2008. Scalin D. 1997).

In this study, alternative energy sources are used to generate both heat and electrical energy from solar energy. In the solar fruit drying system, an electronic circuit with a microcontroller, which can record in the desired time and transfer data with a wireless connection, was designed and controlled and monitored. With the installation of the hardware once, different algorithms have been developed by interpreting the temperature and humidity values from different locations of the system. Under the current conditions, the algorithm in which the highest temperature was obtained in the drying section was used and plum and pear drying was performed. Thus, a system that can be widely used in daily life has been made and a system that can be developed in scientific studies has been obtained. Considering the changes to be made on the hardware, software and environmental conditions, more efficient results will be achieved in the works to be carried out.

\section{Solar Powered Dryer System}

Since it is easy to process in the Solar Energy Drying System, a matt black colored aluminum composite material with $4 \mathrm{~mm}$ thickness is used in the construction of both the drying oven and the solar collecting cage (GITK). $4 \mathrm{~mm}$ polycarbonate sheet is used in the GITK's sun-facing part to allow it to transmit light, be resistant to impacts and not break easily. In addition, the dryer oven door is made of polycarbonate sheet with a drop down. 5 shelves have been constructed in the dryer oven for placing trays with wire grids in the range of $50 \mathrm{~cm} \mathrm{x} 46 \mathrm{~cm}$ and $1 \mathrm{~cm}$ spacing. Two $12 \mathrm{~cm}$ diameter holes were drilled at the bottom of the GITK for air intake and fans were installed accordingly. $3 \mathrm{~cm}$ diameter moist air outlet holes are opened on the upper right and left sides of the drying oven. GITK and drying oven are combined with nut bolts. Feet are mounted in order for the system to stand properly. In addition, wheels are mounted under the GITK for easy transportation. Thus, the system has been made easy to carry like a wheelbarrow by holding the dryer oven feet.

ESP8266 based Nodemcu was used as the controller in the electronic circuit of the system. The $5 \mathrm{~V}$ voltage required for the Nodemcu is provided by the breadboard power card, which is powered by a 12 V 7 A battery. DHT22 sensors are used for temperature and humidity measurement. The $3.3 \mathrm{~V}$ energy required for the sensors is taken over the nodemcu and the data ends are connected to the relevant feet. On the DHT22 sensor input fan \# 1, DHT22 sensor 2 is placed in the middle of the GITK and DHT22 sensor 3 on the middle of the drying oven. Thus, the humidity and temperature of the air coming from outside, inside the GITK and drying oven, were measurable. The circuit is installed on a breadboard and mounted in a waterproof plastic board with dimensions of $25 \mathrm{cmx} 33 \mathrm{cmx} 13 \mathrm{~cm}$. In addition, $12 \mathrm{~V} 7 \mathrm{Ah}$ battery and $12 \mathrm{~V} 3 \mathrm{~A}$ mini solar charger are placed inside the plastic panel. The plastic panel was mounted slidely under the drying oven. A $10 \mathrm{~W} 12 \mathrm{~V}$ solar panel is mounted on the drying oven in an adjustable way so that you can see the sun comfortably. The cables coming from the solar panel, sensors and fans were brought to the plastic panel by passing them through the cable duct. The electronic circuit and battery charging system were installed by making connections in accordance with the design. Thus, the hardware of the control circuit, which will start and stop the fans according to the data from three different sensors, has been made ready.

\section{Experimental Study}

In this study, the purpose of this study is to increase the product quality and shorten the drying time by monitoring the temperature and humidity by controlling the air flow in the solar drying system we set up the hardware and control circuit. In the study we carried out in two separate trials, 5000 gr plum first and then $6000 \mathrm{gr}$ pear were used. In the first attempt, the plums were placed on wire gridded trays in $2500 \mathrm{~g}$ each, divided into four parts and placed by removing the seeds. One of the trays was placed near the dryer, with the other in the shade. The program with the algorithm in Figure 1 was loaded into the microcontroller by writing in Lua language and the system was started.

Drying process started on 26.07.2019 at 13.00 and finished on 01.08.2019 at 13.00. In the second attempt, the pears were divided into 8 pieces on wire gridded trays and placed $3000 \mathrm{~g}$ each. One of the trays was placed in the dryer close to the dryer with the other in the sun. The dryer system was operated under the conditions in the previous experiment. Drying process started on 04.08.2019 at 13.00 and finished on 09.08.2019 at 21.00. Temperature and humidity values are read with a microcontroller every 2 hours and recorded in text file format. When the weight of the dried fruits was measured three times a day and reached the expected weight according to the first and last moisture values, the drying processes were terminated. 


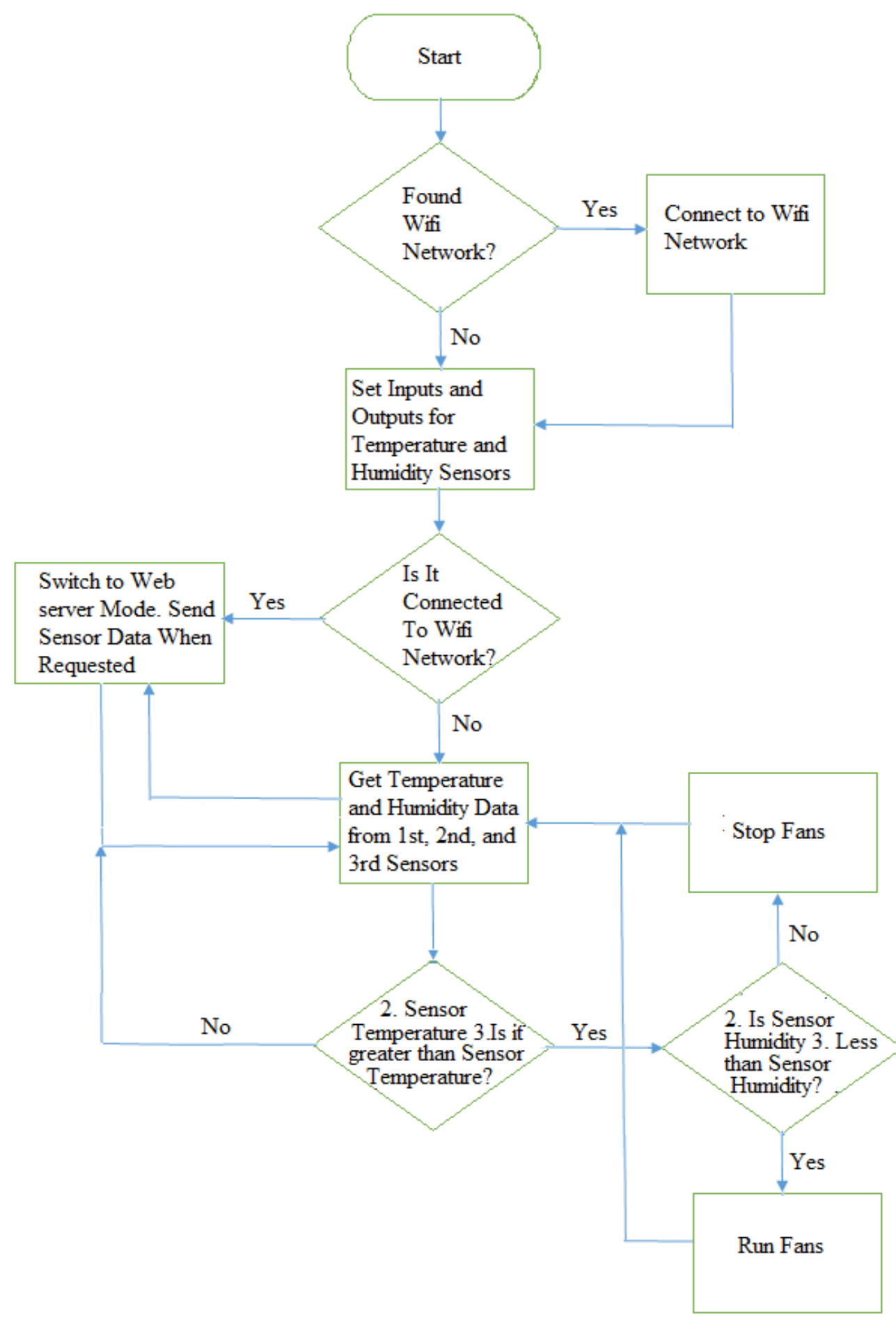

Figure 1. Controlling the drying system automation

The algorithm of the program loaded on the microcontroller

\section{Results}

In the first attempt of plum drying, the temperature and humidity data received from the sensors for the plums placed in the drying oven are shown for the intervals between 07:00 and 21:00, when the change from Figure 2 to Figure 8 is significant. The weight change is given in Figure 9. For the plums outside, a separate measurement was not taken, since the temperature and humidity conditions were considered the same as the inlet temperature and humidity. Data graphics were not prepared on the 4th day of drying, as the visible plums were molded on the outside. 


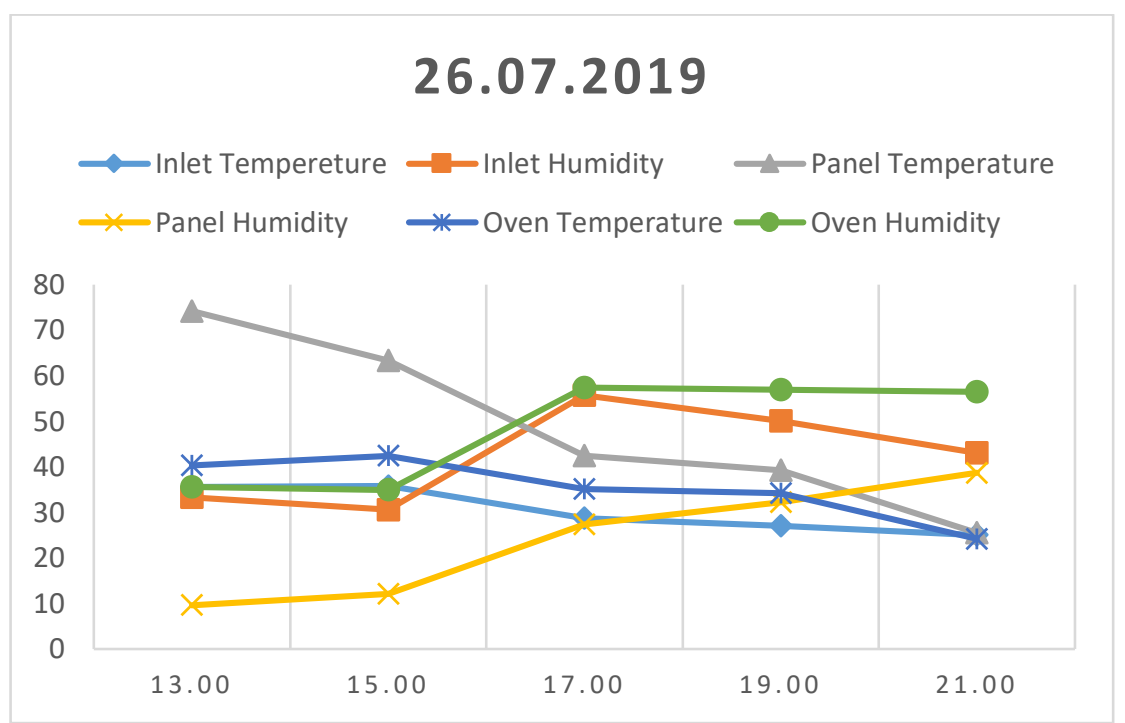

Figure 2. Day 1 Temperature and Humidity Graph

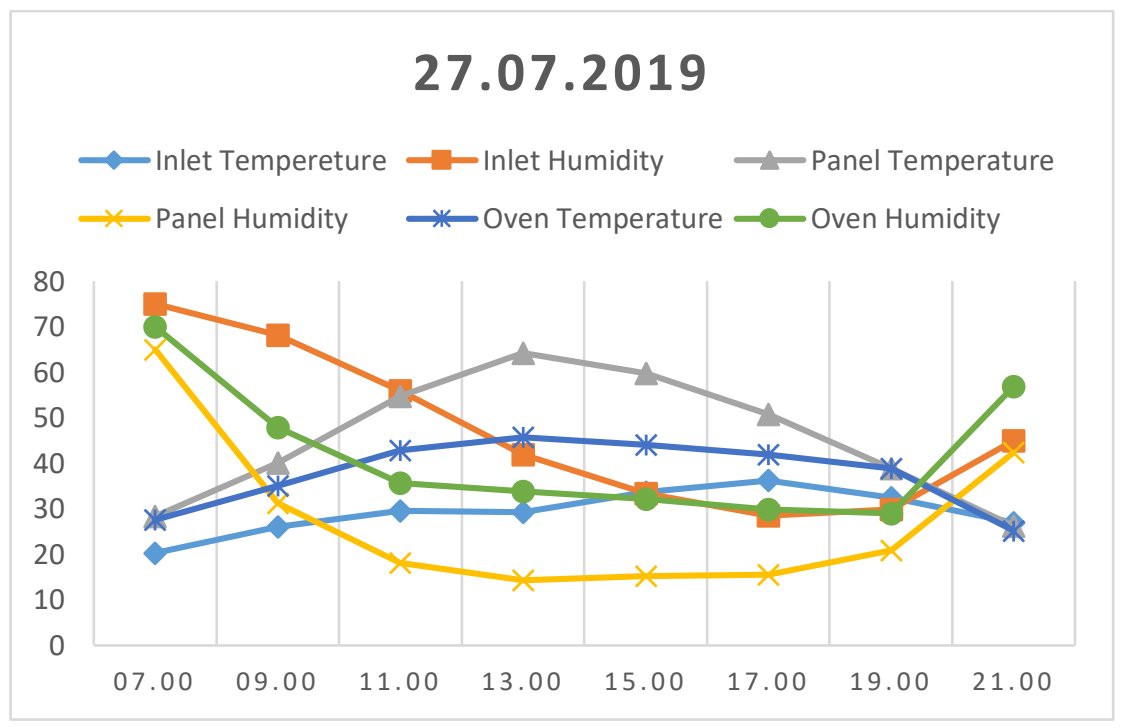

Figure 3. Day 2 Temperature and Humidity Graph

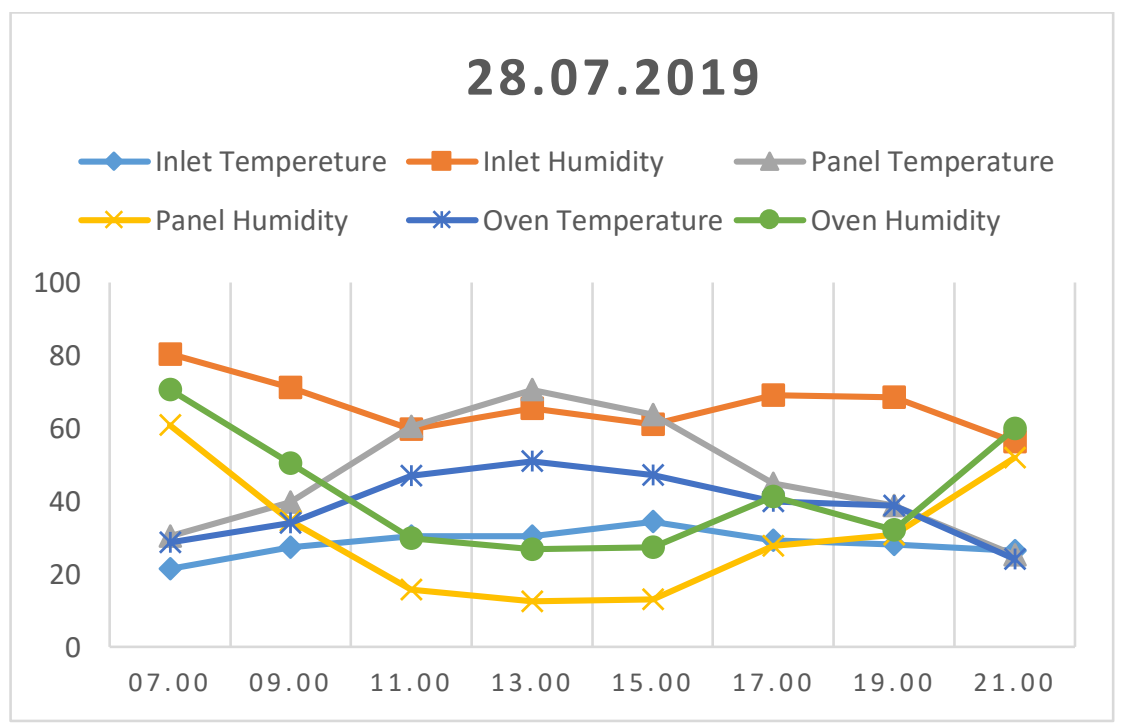

Figure 4. Day 3 Temperature and Humidity Graph 


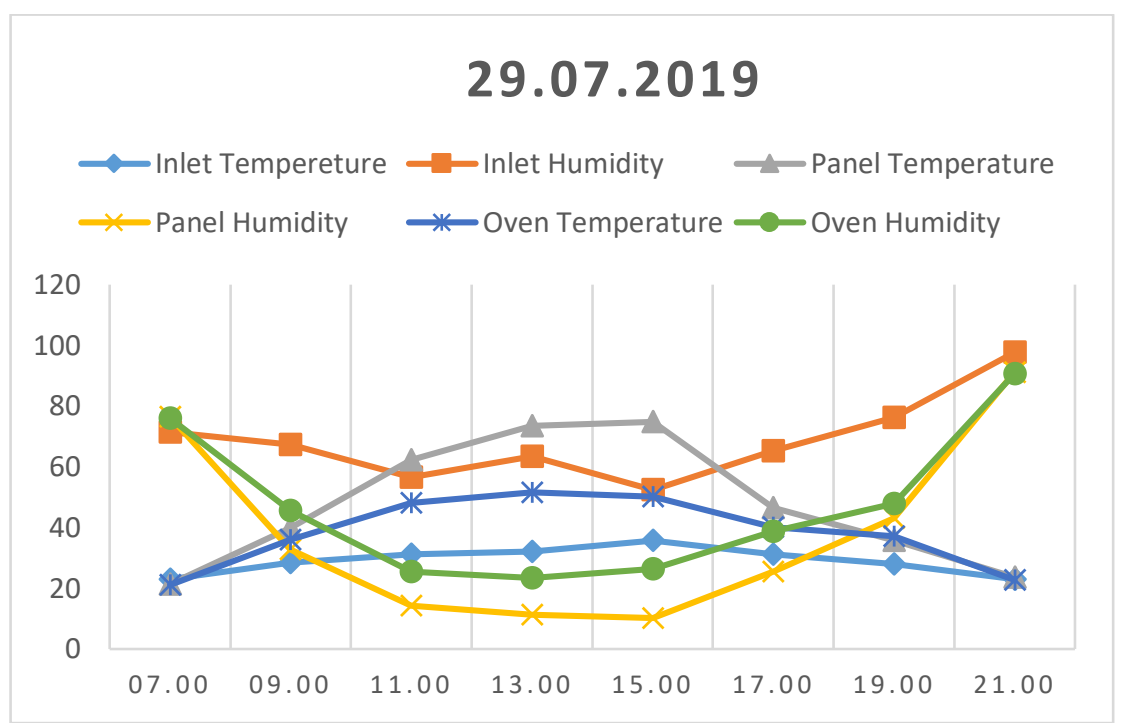

Figure 5. Day 4 Temperature and Humidity Graph

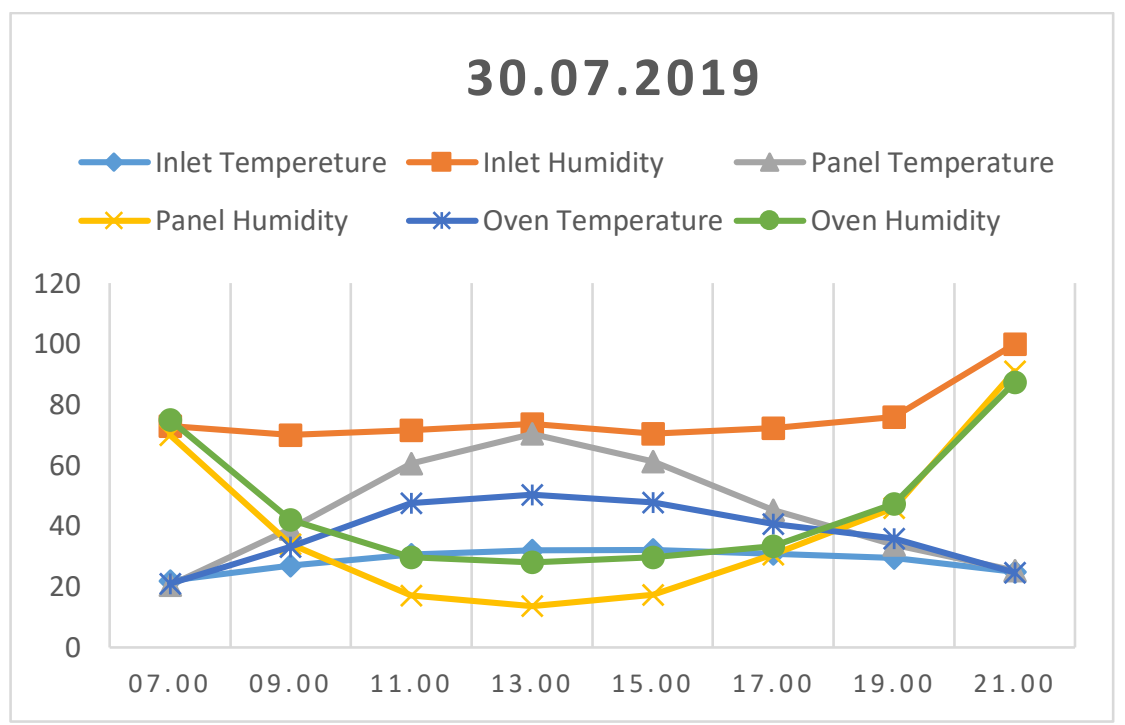

Figure 6. Day 5 Temperature and Humidity Graph

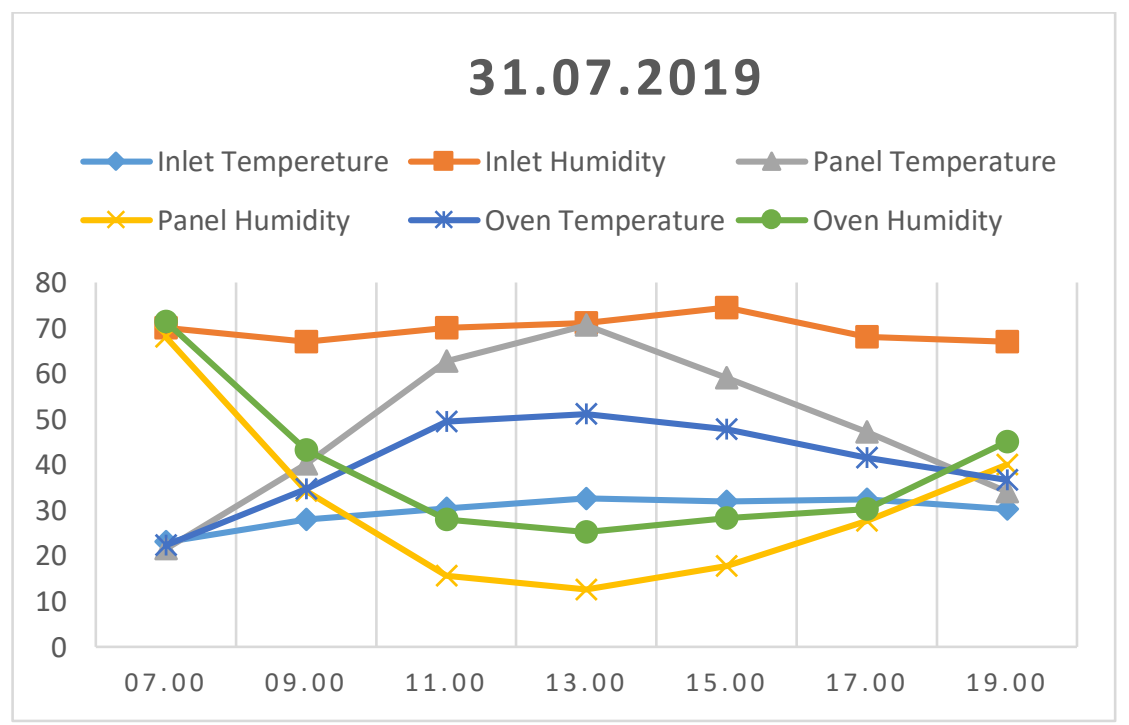

Figure 7. Day 6 Temperature and Humidity Graph 


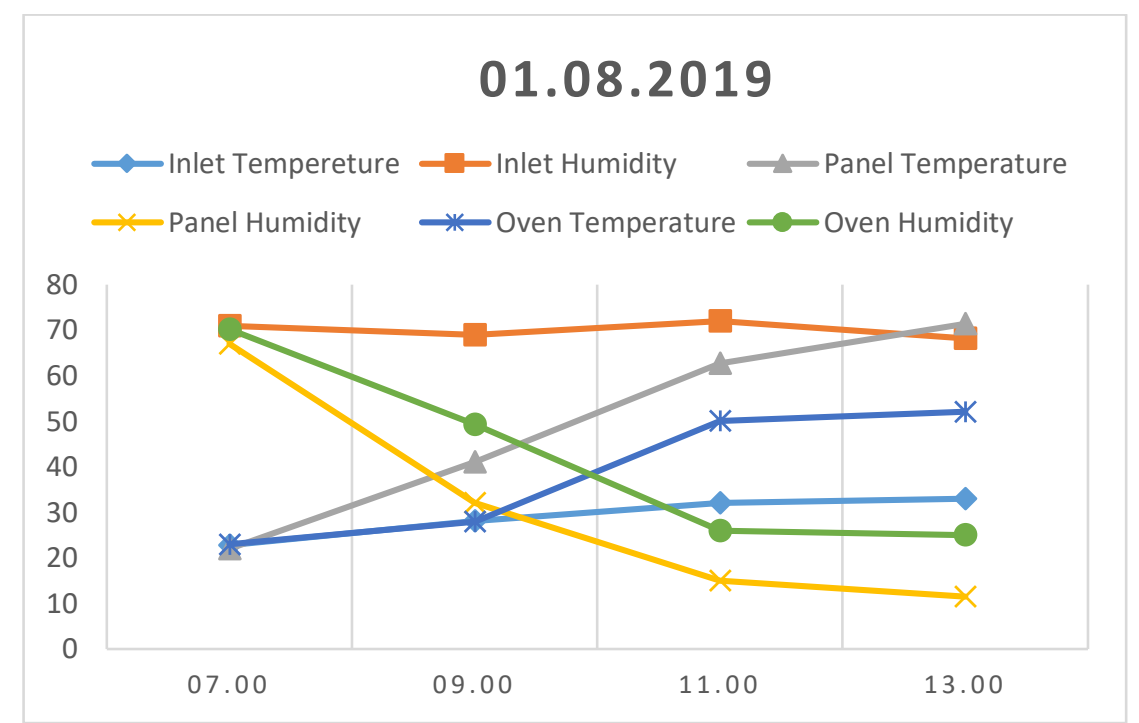

Figure 8. Day 7 Temperature and Humidity Graph

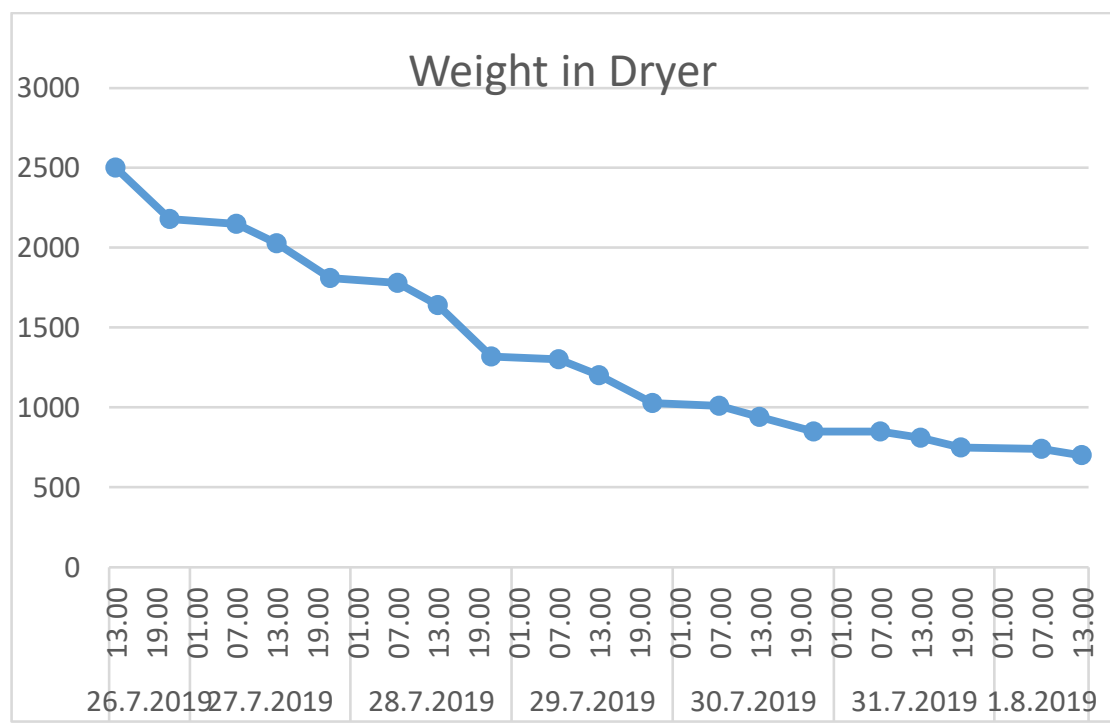

Figure 9. Weight of dried plums in the dryer

In the second trial with pear drying, the results were similar to the plum drying trial, so the temperature and humidity data graphics were not prepared. The weight graphs inside and outside of the dryer are shown in Figure 10 and Figure 11. 


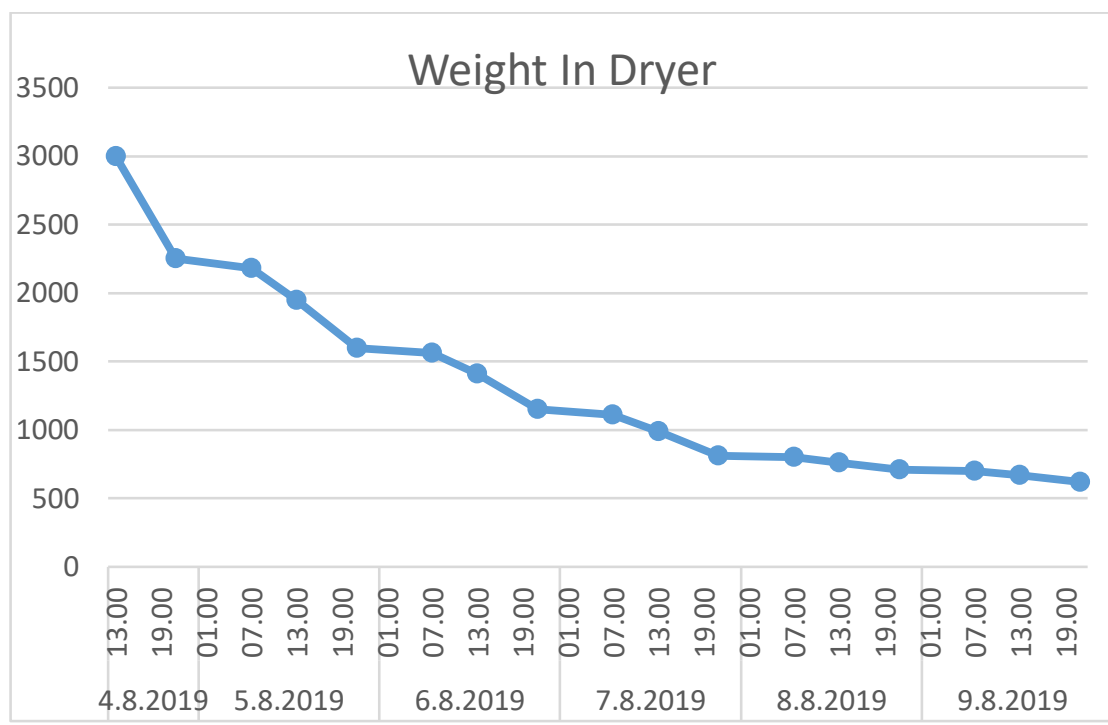

Figure 10. Weight of pears dried in the dryer

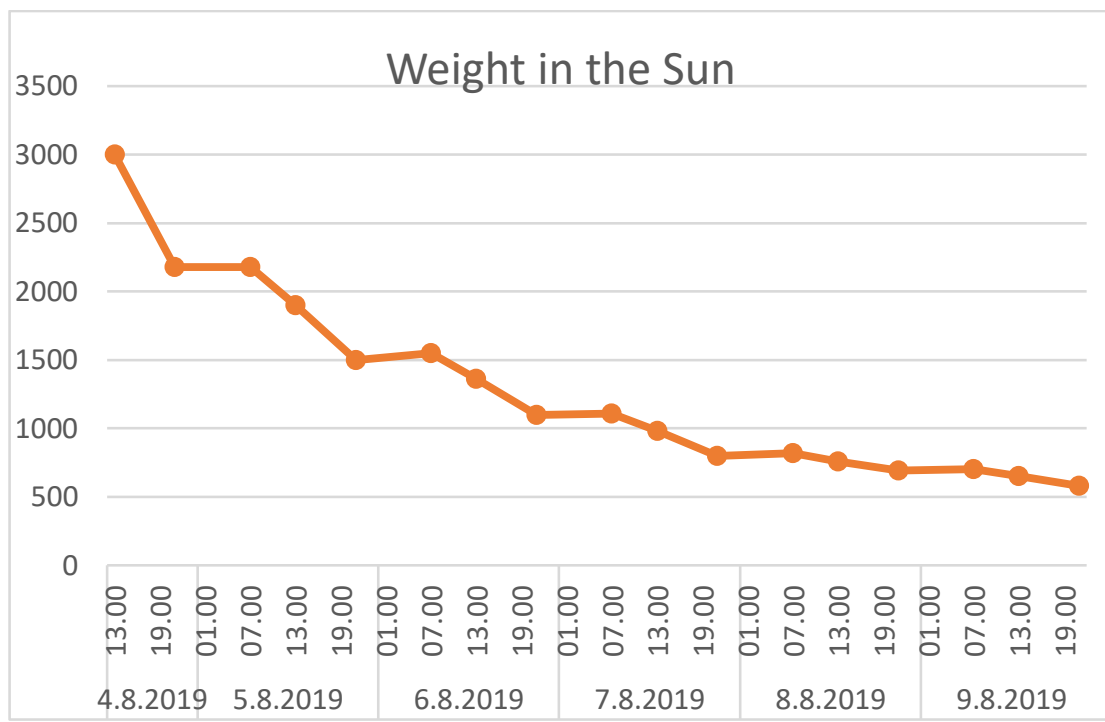

Figure 11. Weight of sun dried pears

As a result of the experiment, the time required to reach the last moisture content from the first moisture content in the plum drying trial was 6 days and 5.5 days in the pear drying trial.

In addition, it was observed that the highest temperature reached 52.1 degrees in the dryer oven where the fruits were placed and 74.8 degrees in the GITK. Since the target to be reached is to increase the temperature of the drying oven, providing faster air flow will increase the temperature in the oven part. In addition, using materials with higher thermal insulation will increase efficiency. When the graphs are analyzed, as expected, the temperature values, which are almost the same in the morning hours, reach their highest values at noon, and come back to the same levels in the evening hours. While the temperature inside the GITK is approximately twice the outdoor temperature at noon, the temperature inside the dryer oven can be 15-20 degrees higher than the outdoor environment. In this case, when the weight graphs are examined, the products in the dryer do not have a rapid moisture loss during the day and little or no moisture at night. In the sun-dried pear in the outdoor environment, there is almost the same moisture loss in the dryer during the daytime, and at night, there is no moisture loss or due to the moisture it increases due to moisture. With the program written on the microcontroller in the dryer, the products are not affected by the raw material since the outside humidity is prevented from entering the indoor air when the indoor humidity passes the indoor humidity.

During the drying experiments, drying times and taste, appearance, hardness, etc. in the product. It was concluded that the expected properties were reached in terms of quality characteristics. 
It was observed that the electronic system with microcontroller, which provides automation of the drying process, affects the drying time by controlling the air flow, and it provides convenience for monitoring the results and saving them in the desired time and storing them as a file.

The system can be made more efficient with the better thermal insulation of the material used in the construction of the dryer, the different designs of GITK, the faster and more variable air flow, the changes in the control program. New additions are made to the system and development studies continue.

\section{References}

Apaydın, N. (2007). Modelling Of A Solar Dryer With Natural Convection Which Will Be Used Around Aydin For Fig Drying, Master Thesis, Adnan Menderes University Graduate School of Natural and Applied Sciences, Aydin, 2-18.

Ceylan, İ., Aktaş, M., Doğan, H. (2006). Apple Drying in the Solar Drying Oven. Journal Of Polytechnic 9 (4), 289- 294.

Ertekin, C., Yaldız, O. (1998). Drying Methods of Some Vegetables, Fruits and Spicy Plants and Solar Dryers Used. 18th National Congress of Agricultural Mechanization Tekirda $\breve{g}, 673-693$.

Gülçimen F., Durmuş A., Durmuş A. (2010). Designing Air Collectors for Use in Drying. Uctea Chamber Of Mechanical Engineers, 38-43.

Hürdoğan E., et al. (2013). Investigation of Applicability of a Solar Energy Supported Desicative Drying System for Drying Food at Low Temperature. 11th National Installation Engineering Congress IZMIR, 875-883.

Mutlu, A., Ergüneş, G. (2008). Determination of tomato drying conditions with solar powered rack dryer in Tokat. Journal of Agricultural Sciences Research, 1(1), 61-68.

Özbalta N., et al. (2003). Development of a Family Solar Dryer. II. Renewable Energy Resources Symposium, 301.

Scalin D. (1997). The Design, Construction and Use of an Indirect, Through-pass, Solar Food Dryer, Home Power Magazine, 57, 62-72

Tosun, N., Bayındır, H., Aydın, H. (2009). A Research On The Establishment Of A Multifunctional Solar Drying System In Diyarbakır Province. V. Renewable Energy Resources Symposium, 8489. 